Spoken sessions

Abstract S60 Table 1 Values of CRP according to patient characteristics, stratified by HIV status

\begin{tabular}{|c|c|c|c|c|c|}
\hline & $\mathrm{N}$ & Median (interquartile range) & & $\mathrm{N}$ & Median (interquartile range) \\
\hline HIV negative & 447 & $22(6-71)$ & HIV positive & 86 & $77(15-166) \neq$ \\
\hline Site & & & Site & & \\
\hline CNS & 11 & $4(3-25)$ * & CNS & 6 & $2(1-4)^{1}$ \\
\hline Skin & 10 & $6(1-19)$ & Pulmonary & 45 & $66(18-166)$ \\
\hline Lymph node & 99 & $8(3-28)$ & Lymph node & 12 & $106(30-142)$ \\
\hline Pulmonary & 228 & $32(11-80)$ & Disseminated & 17 & $103(75-180)$ \\
\hline Disseminated & 10 & $48(27-56)$ & Other & 6 & 79 (22-198) \\
\hline Bone and Joint & 26 & $47(11-69)$ & (includes pleural, & & \\
\hline Pleural/pericardial & 24 & $70(35-125)$ & $\begin{array}{l}\text { pericardial and } \\
\text { abdominal) }\end{array}$ & & \\
\hline Sputum Smear & & & Sputum Smear & & \\
\hline Negative & 87 & $19(7-66)$ * & Negative & 23 & $28(9-66)^{2}$ \\
\hline Positive & 89 & $59(19-111)$ & Positive & 15 & $159(84-248)$ \\
\hline Unknown & 20 & $10(2-23)$ & Unknown & 3 & $3(1-4)$ \\
\hline Culture result & & & Culture result & & \\
\hline Negative & 97 & $8(2-41)$ * & Negative & 16 & $14(1-64)^{3}$ \\
\hline Positive & 317 & $30(9-79)$ & Positive & 67 & $89(30-191)$ \\
\hline Unknown & 12 & $8(1-29)$ & Unknown & 4 & $69(12-130)$ \\
\hline
\end{tabular}

S61 HIGH LEVELS OF LATENT TB INFECTION, BLOOD BORNE VIRUSES, POOR TREATMENT OUTCOMES AND UNMET NEED AMONG HARD TO REACH GROUPS IN LONDON: THE TB REACH STUDY

${ }^{1} \mathrm{G}$ Ferenando, ${ }^{1} \mathrm{~S}$ Hemming, ${ }^{3} \mathrm{~S}$ Yates, ${ }^{1} \mathrm{~L}$ Possas, ${ }^{1} \mathrm{E}$ Garber, ${ }^{2} \mathrm{~V}$ Gant, ${ }^{3} \mathrm{R}$ Aldridge, ${ }^{1} \mathrm{AM}$ Geretti, ${ }^{1} \mathrm{~J}$ Harvey, ${ }^{3} \mathrm{~A}$ Hayward, ${ }^{1} \mathrm{M}$ Lipman, ${ }^{1} \mathrm{TD}$ McHugh, ${ }^{2} \mathrm{~A}$ Story. ${ }^{1}$ Royal Free London NHS Foundation/University College London, London, UK; ${ }^{2}$ University College London Hospitals, London, UK; ${ }^{3}$ Research Department of Infection and Population Health, University College London, London, UK

\subsection{6/thoraxjnl-2014-206260.67}

Background There are high rates of active tuberculosis (TB) in London's hard to reach groups (homeless people, substance misusers and prisoners). However no systematic data are available regarding the prevalence of latent $\mathrm{TB}$ infection (LTBI) and blood borne viruses (BBV) - HIV, Hepatitis B and C (HBV, HCV). Hard to reach groups often present late for healthcare. We undertook a TB/BBV screening programme to assess the prevalence of LTBI and co-infection with BBVs within homeless hostels, drug services and a prison in London. We also investigated management outcomes in those referred on to healthcare services.

Design/method Recruitment took place from May 2011-June 2013. Service users screened for TB on a mobile chest x-ray unit and in prison using the static digital $\mathrm{x}$-ray machine were approached and, with consent, blood was drawn for IGRA (Quantiferon In-Tube) and HIV, HCV and HBV. Results were provided to participants with onward referral to healthcare services in line with current guidance. Treatment outcomes were collected via telephone follow up one year post referral for the positive cases.

Results Prison $(\mathrm{n}=511)$ (Table 1$)$

LTBI: $65(13 \%)$ participants were IGRA positive [3(5\%) coinfected with $\mathrm{HCV}]$. Of these, 37(57\%) were referred for preventive treatment, 16(43\%) did not attend (DNA) appointments and were discharged or were lost to follow up (LFU). Of the 15 who commenced treatment, 9(60\%) completed treatment.

HCV: 22 participants were positive and referred, of which 11 $(50 \%)$ DNA/LFU, $11(50 \%)$ were under review and none commenced treatment.
HBV: 10 participants were positive, of which 6(60\%) DNA/ LFU, 4(40\%) were under review and none commenced treatment.

There were no HIV positives.

Community $(\mathrm{N}=696)$ (Table 1$)$

LTBI: $116(17 \%)$ participants were IGRA positive [22(19\%) co-infected with HCV]. Of the 14(12\%) referred to services, 8 $(57 \%) \quad$ DNA/LFU and 3(21\%) commenced treatment (2 completed).

HCV: 84 were positive and referred (8 new diagnosis), 42 (50\%) DNA/LFU/declined referral, and 37(44\%) under review. Five (6\%) commenced treatment, one completed.

HBV: 9 participants had current infection, none started treatment; 6 were under review and 3 DNA/LFU.

HIV: 9 participants were positive and known to healthcare services.

Conclusion The prevalence of LTBI, BBVs and co-infection within the hard to reach group is high compared to the general population with fewer patients starting TB prophylaxis/HCV treatment. The high overall rates of DNA/LFU (47\%) seen indicate that current approaches to onward referral and retention in care for this group appear to be poor and effective measures to improve engagement with clinical services are essential.

This study was supported by NIHR Programme Grant for Applied Research (RP-PG-0407-10340).

\section{S62 RISK FACTORS FOR IGRA POSITIVITY IN CONTACTS OF ACTIVE TUBERCULOSIS IN A UK HIGH-PREVALENCE SETTING}

AC Repossi, RD Turner, GH Bothamley. Homerton University Hospital NHS Foundaiton Trust, London, UK

\subsection{6/thoraxjn-2014-206260.68}

Background Interferon-gamma release assays (IGRAs) are being used to confirm significant exposure to tuberculosis (TB) after a positive tuberculin skin test (TST). We explored the variability 
Abstract S61 Table 1

\begin{tabular}{|c|c|c|c|c|c|c|c|c|c|c|c|c|c|c|c|c|c|}
\hline \multirow{5}{*}{\begin{tabular}{|l} 
Healthcare \\
Engagement
\end{tabular}} & \multirow{4}{*}{\begin{tabular}{|l}
$\begin{array}{l}\text { Outcomes at } 12 \text { months - } \\
\text { categories }\end{array}$ \\
On treatment \\
Completed treatment
\end{tabular}} & \multicolumn{8}{|c|}{ Prison $\mathrm{N}=511$ screened } & \multicolumn{8}{|c|}{ Community N= 696 screened } \\
\hline & & \multicolumn{2}{|c|}{ LTBI $n(\%)$} & \multicolumn{2}{|c|}{$\operatorname{HCV} n(\%)$} & \multicolumn{2}{|c|}{ HBV $n(\%)$} & \multicolumn{2}{|c|}{ HIV $n(\%)$} & \multicolumn{2}{|c|}{ LTBI $n(\%)$} & \multicolumn{2}{|c|}{ HCV $n(\%)$} & \multicolumn{2}{|c|}{ HBV $n(\%)$} & \multicolumn{2}{|c|}{ HIV n(\%) } \\
\hline & & $1(3 \%)$ & \multirow{3}{*}{$\begin{array}{c}15 \\
(41 \%)\end{array}$} & 0 & \multirow{3}{*}{0} & 0 & \multirow{3}{*}{0} & 0 & \multirow{3}{*}{0} & 0 & \multirow{3}{*}{$\begin{array}{c}3 \\
(21 \%)\end{array}$} & $3(4 \%)$ & \multirow{3}{*}{$5(6 \%)$} & 0 & \multirow{3}{*}{0} & 9 & \multirow{3}{*}{$\begin{array}{c}9 \\
(100 \%)\end{array}$} \\
\hline & & $9(24 \%)$ & & 0 & & 0 & & 0 & & $2(14 \%)$ & & $1(1 \%)$ & & 0 & & 0 & \\
\hline & Incomplete treatment & $5(14 \%)$ & & 0 & & 0 & & 0 & & $1(7 \%)$ & & $1(1 \%)$ & & 0 & & 0 & \\
\hline \multirow{2}{*}{$\begin{array}{c}\text { Attended, no } \\
\text { treatment }\end{array}$} & Seen, discharged & $5(14 \%)$ & \multirow{2}{*}{$\begin{array}{c}6 \\
(16 \%)\end{array}$} & $1(5 \%)$ & \multirow{2}{*}{$\begin{array}{c}11 \\
(50 \%)\end{array}$} & 0 & \multirow{2}{*}{$4(40 \%)$} & 0 & \multirow{2}{*}{$\mathbf{0}$} & $3(21 \%)$ & \multirow{2}{*}{$\begin{array}{c}3 \\
(21 \%)\end{array}$} & $4(5 \%)$ & \multirow{2}{*}{$\begin{array}{c}37 \\
(44 \%)\end{array}$} & $2(22 \%)$ & \multirow{2}{*}{$\begin{array}{c}6 \\
(67 \%)\end{array}$} & 0 & \multirow{2}{*}{0} \\
\hline & Under review, no treatment & $1(3 \%)$ & & $10(45 \%)$ & & $4(40 \%)$ & & 0 & & 0 & & $33(39 \%)$ & & $4(45 \%)$ & & 0 & \\
\hline \multirow{3}{*}{$\begin{array}{c}\text { No } \\
\text { engagement } \\
\text { with services }\end{array}$} & DNA, discharged/ LFU & $16(43 \%)$ & \multirow{2}{*}{$\begin{array}{c}16 \\
(43 \%)\end{array}$} & $11(50 \%)$ & \multirow{2}{*}{$\begin{array}{c}11 \\
(50 \%)\end{array}$} & $6(60 \%)$ & \multirow{2}{*}{$6(60 \%)$} & 0 & \multirow{2}{*}{$\mathbf{0}$} & $7(50 \%)$ & \multirow{2}{*}{$\begin{array}{c}8 \\
(57 \%)\end{array}$} & $40(48 \%)$ & & $3(33 \%)$ & 3 & 0 & \\
\hline & Declined referral & 0 & & 0 & & 0 & & 0 & & $1(7 \%)$ & & $2(2 \%)$ & & & $(33 \%)$ & 0 & \\
\hline & TOTAL REFERRALS: & & 37 & & 22 & & 10 & & 0 & & 14 & & 84 & & 9 & & 9 \\
\hline
\end{tabular}

of a positive test in a large UK TB clinic amongst contacts of active disease.

Methods The records of all individuals notified with active TB and of their screened contacts from 2012-3 were reviewed retrospectively. Uni- and multivariate analysis identified variables associated with active TB and/or QuantiFERON ${ }^{\circledR}$ test positivity in contacts.

Results Of 203 notified tuberculosis index cases, 470 contacts were screened. 116 had immunological evidence of TB exposure including 11 with active disease. The estimated background rate of positive TB immune response was $18 \%$ and was the same in contacts of index cases who were later denotified (7/39) as in contacts of extrapulmonary disease (24/132).

On univariate analysis, index case variables associated with a positive TST and IGRA were a pulmonary vs. extrapulmonary site of disease (OR 2.1; 95\% confidence interval 1.3-3.5) and, for contacts of pulmonary TB (PTB), presence of cough (2.5; $1.1-4.0)$, duration of cough $(\mathrm{p}=0.04)$,sputum smear positivity $(1.7 ; 1.0-2.8)$, sputum smear grade $(\mathrm{p}=0.02)$, radiographic extent of disease $(\mathrm{p}=0.008)$, and perhaps pulmonary cavities $(1.6 ; 1.0-2.6)$. No effect was detected of gender, smoking status, or TB strain of the index case (Beijing or Cameroon vs. other lineage), or nature of contact (household vs. other), even when considering only child contacts.

Contact variables associated with positive tests were birth in a high TB prevalence country $(2.3 ; 1.4-3.6)$, age $\geq 12$ years $(2.0$; $1.2-3.3)$, smoking $(2.2 ; 1.0-5.1)$ and perhaps alcohol excess (3.2; 0.9-10.7), but not diabetes or BCG vaccination. There were insufficient data to investigate an effect of HIV and homelessness. Contact country of birth $(1.9 ; 1.1-3.1)$ and index site of disease $(2.0 ; 1.2-3.4)$, sputum smear positivity $(2.6 ; 1.3-5.6)$ and radiographic extent of disease $(\mathrm{p}=0.008)$ remained significant on multi-variate analysis.

Conclusion The likelihood of significant TB exposure is a consequence of bacillary load, radiographic extent of disease and coughing behaviour.

\section{S63 INVESTIGATION OF SERUM BIOMARKERS IN TUBERCULOSIS DIAGNOSIS}

CD Tweed, GH Bothamley. Homerton University Hospital, London, UK

10.1136/thoraxjnl-2014-206260.69
Introduction In screening for tuberculosis (TB), we need to distinguish between active and latent TB. In those with a positive interferon-gamma release assay (IGRA) additional tests are required to identify active TB. Proteomic fingerprinting suggested that four proteins (C-reactive protein (CRP), transthyretin, neopterin, and serum amyloid A (SAA)) might be able to distinguish active from latent disease. ${ }^{1}$

Methods Patients were grouped to reflect different stages of infection and those with latent TB were followed for over eight years. These groups were: 1) Smear-positive TB ( $\mathrm{n}=20), 2)$ Smear-negative/culture-positive TB ( $\mathrm{n}=12), 3)$ Recent TB contacts with positive interferon-gamma release assay (IGRA) ( $\mathrm{n}=$ 15), and 4) No TB detected with firm alternative diagnosis ( $\mathrm{n}=$ 12). All patients in groups 1 to 3 and $25 \%$ of group 4 were IGRA positive. Serum samples were collected and enzyme-linked immunosorbent assays (ELISAs) were performed to measure Creactive protein, transthyretin, neopterin, and serum amyloid $\mathrm{A}$ found in the serum samples from each group. Standard cut-off values were used for each protein and results labelled as either positive or negative. Chi-square calculations were used to determine the significance of the results in differentiating between active $\mathrm{TB}$, latent $\mathrm{TB}$, and absence of $\mathrm{TB}$ infection.

\begin{tabular}{l}
$\begin{array}{l}\text { Abstract S63 Table } 1 \\
\text { results for each biomarker as a percentage of the total in the group }\end{array}$ \\
\hline
\end{tabular}

